CLINICAL CASE

\title{
A SPECIFIC CASE OF APPENDICITIS IN THE ELDERLY - AN EXPERIENCE FOR THE YOUNG CLINICIAN
}

\author{
I. R. Toader ${ }^{1}$, Mihaela Vîlcu ${ }^{2}$, S.A.A. Shadaloey ${ }^{1}$, C.A. Vişan ${ }^{1}$, I. Brezean ${ }^{1,2}$ \\ ${ }^{1}$ The University of Medicine and Pharmacy "Carol Davila", Bucharest, Romania \\ ${ }^{2}$ General Surgery Clinic "Ion Juvara”, "Ion Cantacuzino” Clinical Hospital, Bucharest, Romania \\ Corresponding author: Toader Radu Ionuț \\ Phone no. 0040763662439 \\ E-mail: tr.toader@gmail.com
}

\begin{abstract}
Appendicitis is an inflammatory disease caused by obstruction of the appendiceal lumen. It represents one of the most common abdominal pathologies in clinical practice. Appendicitis has a well-defined range of signs and symptoms but is harder to diagnose in elderly patients because of less specific symptomatology, a wide differential diagnosis, and communication problems. The perforation rate in the elderly is 50-70\%, rising with age (particularly above age 80), compared with a perforation rate of 20-30\% in the general population, suggesting that symptoms may appear mild while the case may actually be severe. With rising life expectancy and thus an increase in elderly patients presenting with appendicitis symptoms, and to further the experience of the young clinician, we report the case of an 88-year old woman who was admitted to the hospital's emergency ward, with acute hypogastric pain that radiated to the back and to the entire abdomen. Appendicitis was diagnosed, followed by surgical procedure and the patient recovered well.
\end{abstract}

Keywords: appendicitis, inflammatory disease, hypogastric pain

\section{Introduction}

Appendicitis is an inflammatory disease caused mainly by obstruction of the appendiceal lumen. The obstruction can be caused by fecaliths, hypertrophy of lymphoid tissue, inspissated barium, tumors, vegetable and fruit seeds, and intestinal parasites.

Epidemiological data shows that it is a disease of the young ( $40 \%$ of cases occur in patients aged between 10 and 29 years) with a slight male to female predominance (1.2 to $1.3: 1$ ) $[1,2]$.

The prime symptom of acute appendicitis is abdominal pain, diffusely centered in the lower epigastrium or umbilical area, which later localizes to the right lower quadrant. It is usually accompanied by weight loss (anorexia) and vomiting.

The physical examination shows that the patient prefers to lie supine, with the thighs drawn up (particularly the right thigh). The classic right lower quadrant physical signs are present (psoas sign, obturator sign, McBurney, Rovsing,). Cutaneous hyperesthesia, muscular resistance to palpation of the abdominal, or reflex muscular rigidity, due to peritoneal inflammation, are also found. Furthermore, temperature may be elevated but is rarely $>1{ }^{\circ} \mathrm{C}$ [3]. 
Laboratory findings show mild leukocytosis, from $10 \mathrm{k}$ to $18 \mathrm{k}$ cells / $\mathrm{mm} 3$ (80-85\% of adults with appendicitis have a white blood cell (WBC) count greater than 10,500 cells $/ \mu \mathrm{L}$ ). Usually WBC tends to be below $18 \mathrm{k}$ if uncomplicated $[4,5]$.

Imaging studies consisting of plain radiography or barium enema are frequently obtained as part of the evaluation of the patient but are rarely helpful in diagnosing acute appendicitis. Selective use of CT scanning must also be considered. Ultrasonography is an accurate as well as time and cost efficient testing method. The increased use of ultrasonography, computed tomography and laparoscopy have not, however, reduced the rate of misdiagnosis of appendicitis (15.3\%) and the rate of appendiceal rupture.

Clinical scoring systems (Mantrels, Alvarado) are frequently used by young clinicians to diagnose acute appendicitis because of their simplicity. (Tabel 1)

\begin{tabular}{lc}
\hline \multicolumn{1}{c}{$\begin{array}{c}\text { Mantrels Scoring System } \\
\text { Characteristic }\end{array}$} & Score \\
\hline $\begin{array}{l}\text { M: Migration of pain to right lower } \\
\text { quadrant }\end{array}$ & 1 \\
\hline A: Anorexia & 1 \\
\hline N: Nausea and vomiting & 1 \\
\hline T: Tenderness in right lower quadrant & 2 \\
\hline R: Rebound pain & 1 \\
\hline E: Elevated temperature & 1 \\
\hline L: Leukocytosis & 2 \\
\hline $\begin{array}{l}\text { S: Shift of white blood cell count to } \\
\text { the left }\end{array}$ & 1 \\
\hline \multicolumn{2}{c}{ Total } \\
\hline Tabel 1 - Mantrels Scoring System Characteristic
\end{tabular}

McKay and Shepherd recommended that patients with a Mantrels score of $0-3$ could be discharged without imaging, that those with scores of 7 or above receive surgical consultation, and those with scores of 4-6 undergo CT evaluation [6].

When considering elderly patients, the young clinician must be mindful that the classic periumbilical pain migrating to the right lower quadrant is infrequently reported. Elderly patients may present with lower abdominal pain, but localized right lower quadrant tenderness is present in only $80-90 \%$ of patients. The usefulness of the Alvarado score appears to diminish in the elderly: fewer than $50 \%$ of the elderly with appendicitis have an Alvarado score of $\geq 7.66$. Although there are currently no criteria that definitively identify elderly patients with acute appendicitis who are at risk of rupture, the condition must be considered for those with a temperature of $>38^{\circ} \mathrm{C}\left(100.4^{\circ} \mathrm{F}\right)$ and a shift to the left in leukocyte count of $>76 \%$, particularly if they are male, losing weight (anorexic), or with pain of long duration before admission [7]. Moreover, the increase in age (particularly above age 80 ) also represents an increase in the perforation rate [8].

\section{Case presentation}

We report the case of an 88-year old woman who was admitted to the hospital's emergency ward with acute hypogastric pain that radiated to the back and to the entire abdomen. The pain had appeared a month prior and had progressed in intensity until hospitalization. The pain did not disappear after administering NSAIDs. The patient had also not had a bowel movement for three days before admission.

The clinical examination showed periumbillical erythema (Figure 1) that extended towards the flanks, abdominal tenderness, reduced thoracic expansions, lumbar and thoracic spondylosis and scoliosis, a wellrepresented fatty tissue and bilateral leg edema. Because of the pain, the patient remained in a constant rigid position with her thighs slightly flected on her body.

The signs and symptoms thus far suggested an infectious etiology, making the physician also consider erysipelas, cellulitis, parietal necrosis.

A full blood count was done first; the analysis showed that the patient was suffering from sepsis at the time of admission. (WBC $23 \mathrm{~K}, \mathrm{NE} 17 \mathrm{~K}$, serum glucose $138 \mathrm{mg} / \mathrm{dl}$, CRP $141 \mathrm{mg} / \mathrm{L})$ [9].

A plain abdominal radiography showed some air fluid levels on the intestine though not generalized. An ultrasonographic study showed a 4-6cm hypoechoic mass (Figure 2), which was behind and had infiltrated the abdominal muscles, blocking the aspect of the tissues behind it. 
Thus far the laboratory findings and imaging studies supported our clinical diagnosis of appendicitis, as well as adding the possibility of a parietal abscess based on the ultrasonographic findings.

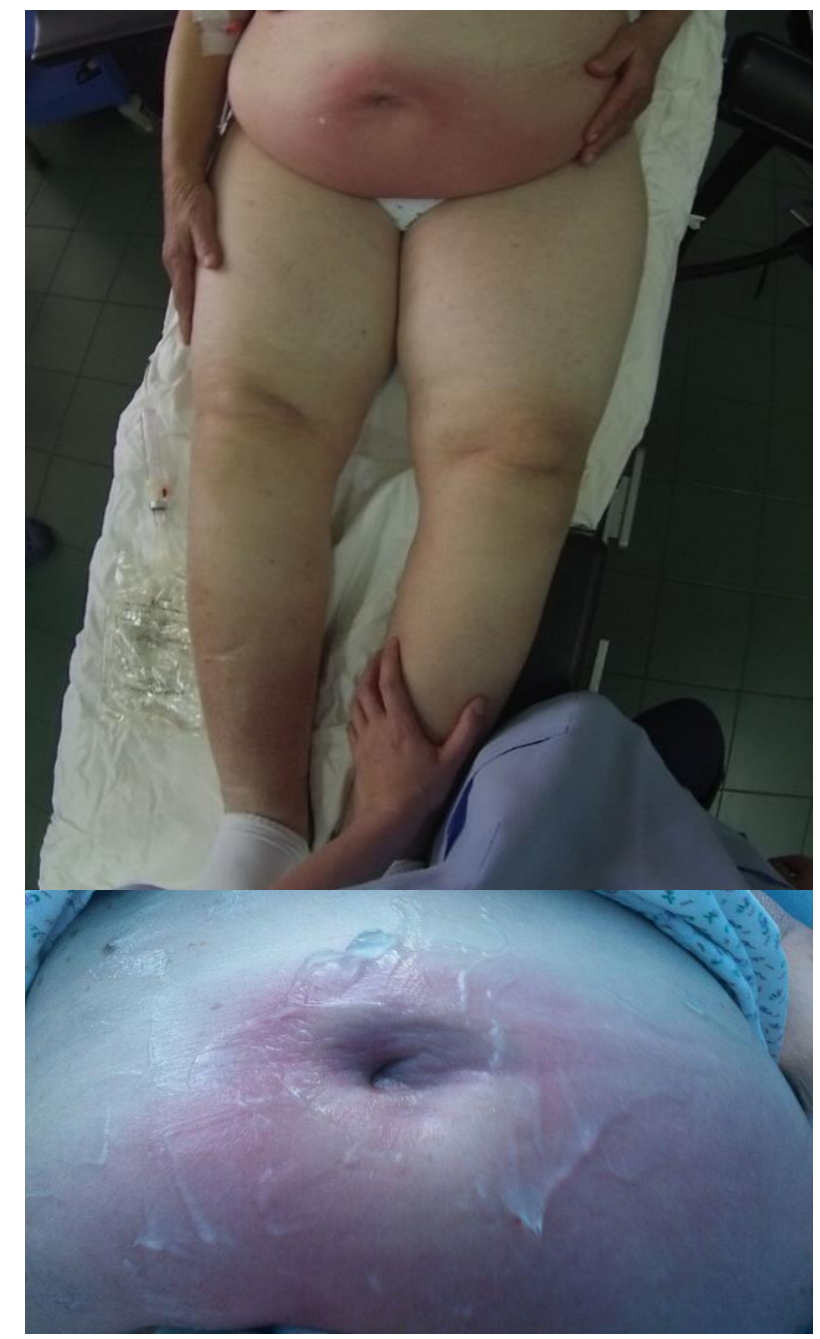

Figure 1 - The inspection of the erythematous periumbilical region (covered with ultrasound gel).

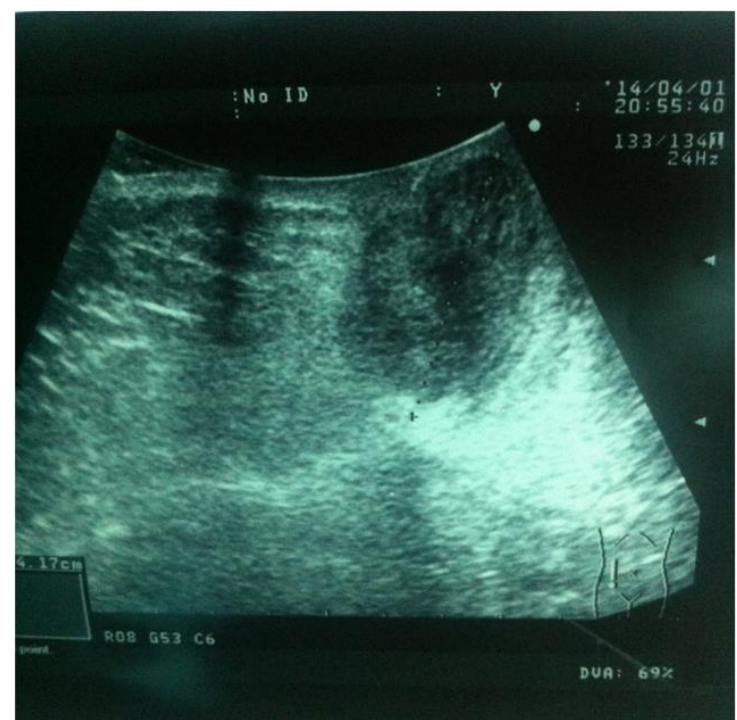

Figure 2 - Hypoechoic mass; 4-6cm in diameter
Preoperative antibiotherapy was administered. The patient was put under general anesthesia. An urgent exploratory laparotomy was performed. The midline incision, which avoided the umbilical scar, was filled by yellow opalescent liquid (Figure 3), also necrosis and inflammation of the surrounding tissue could be seen. A sample was taken for further analysis.

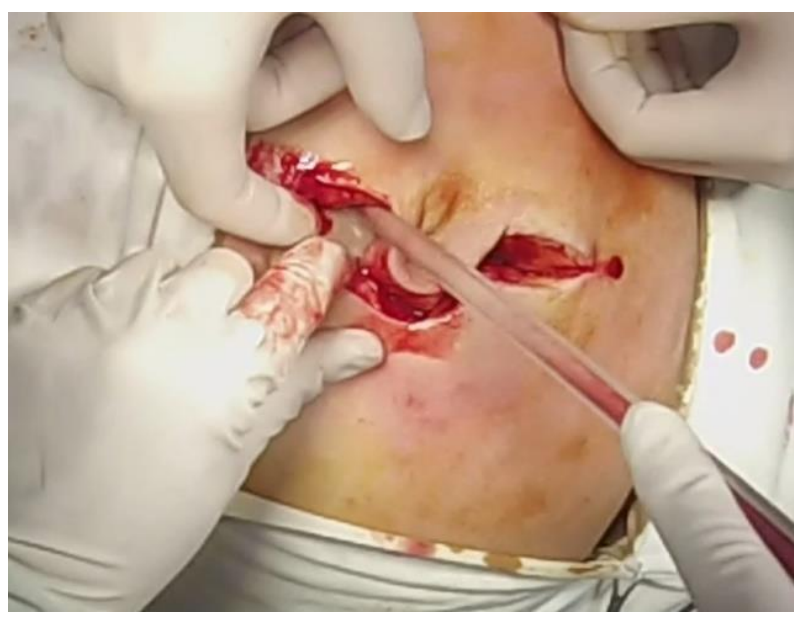

Figure 3 - A yellow suppuration can be seen in the midline incision

After evaluating and, considering the affected umbilical scar, the operating surgeons removed the affected tissue (Figure 4). The entire incision was also extended in a caudal fashion because of the extent of the lesion.

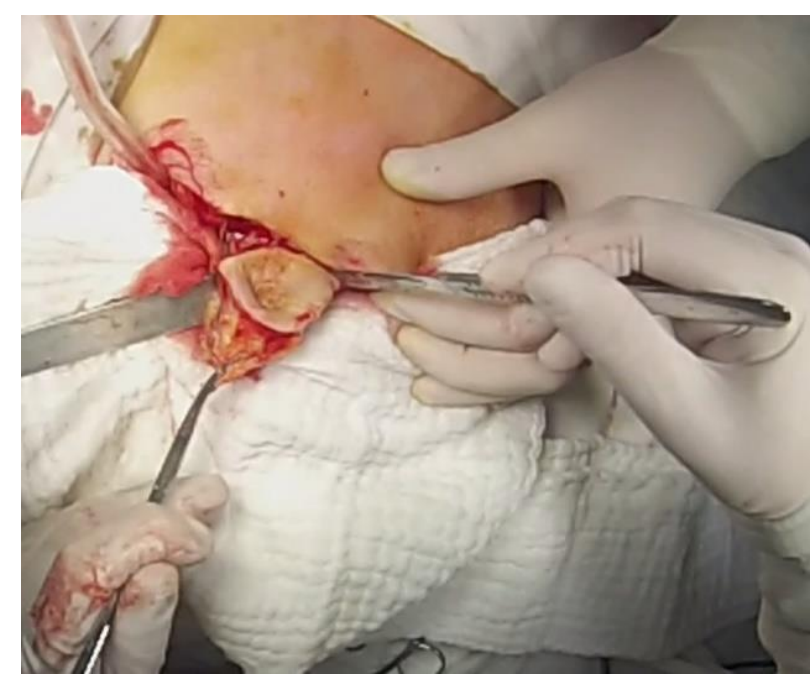

Figure 4 - The excision of the umbilical scar

After entering the peritoneal cavity, a necrotic mass could be seen (Figure 5), containing parts of the great omentum, ileum, mezoileum, and fatty tissue. From between the affected tissue a thick yellow secretion could be seen. 


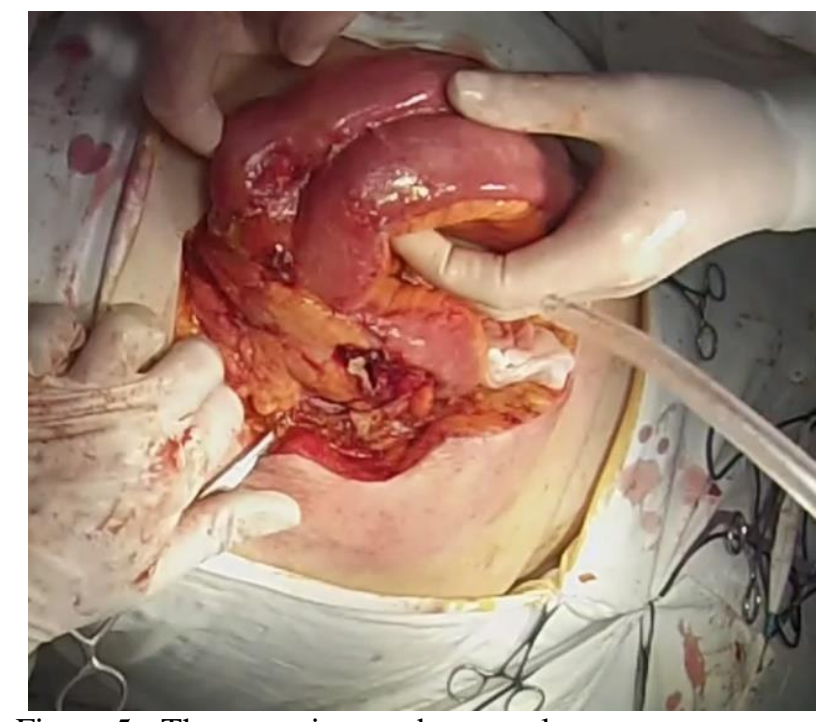

Figure 5 - The necrotic pseudotumoral mass

At this stage of the procedure the surgeons were considering an enteral necrosis consequent to a tumoral process. Carefully analyzing along the length of the lesion, a cecal perforation was found and next to it, a gangrenous appendix.

After suturing the cecal defect (Figure 6) caused by the fistula and the removal of the appendix, the afferent and efferent viable parts of the ileum were identified. The afferent side of the ileum was ligatured and a transversal incision was made. Afterwards, using a Ligasure device, the entire mesentery of the affected ileum was dissected, up to the efferent viable part (Figure 7).

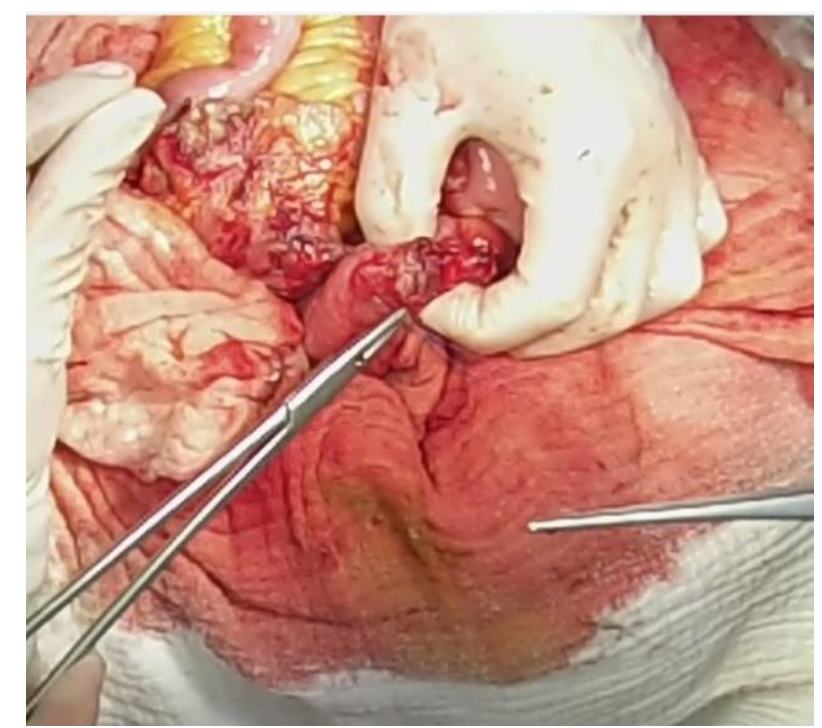

Figure 6 - Suturing the cecal fistula

The efferent side $(15 \mathrm{~cm}$ from the ileocecal valve) was closed in a bursa manner. The entire pseudotumoral mass and the appendix were sent for a histopathological examination (Figure 8).

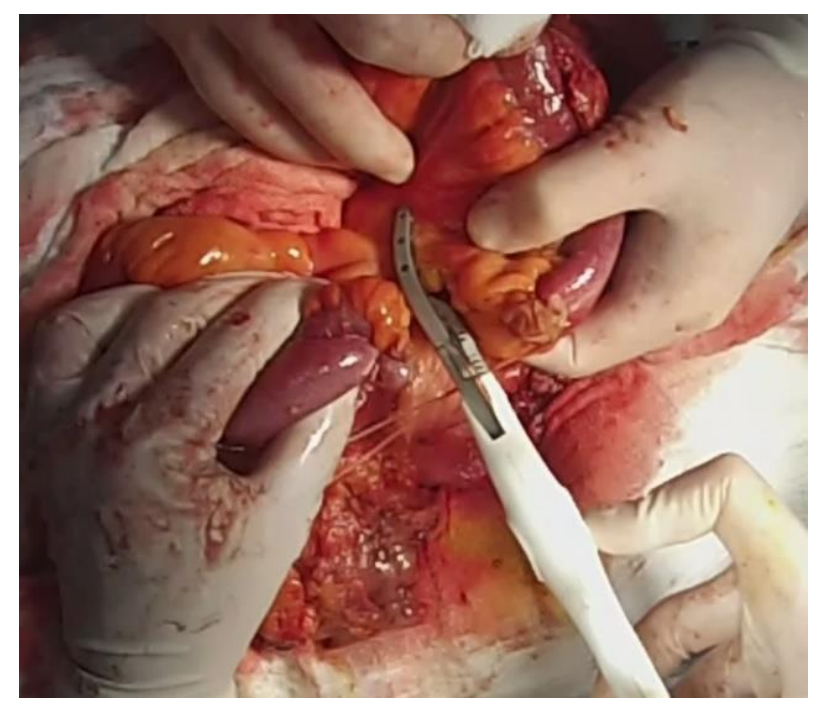

Figure 7 - The dissection of the mesentery

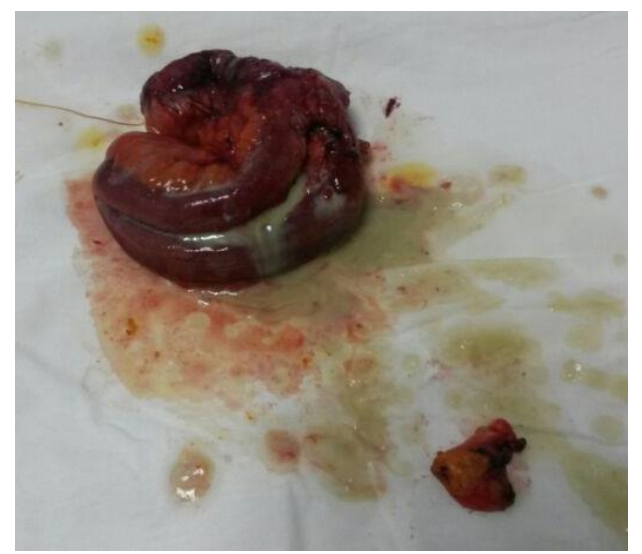

Figure 8 - Pseudotumoral mass and appendix resection pieces

Following the resection, an ileostoma was made from the afferent side of the ileum (Figure 9). Drainage tubes were placed in the Douglas pouch, the affected muscle tissue was resected, and a multilayer manual suture was performed.

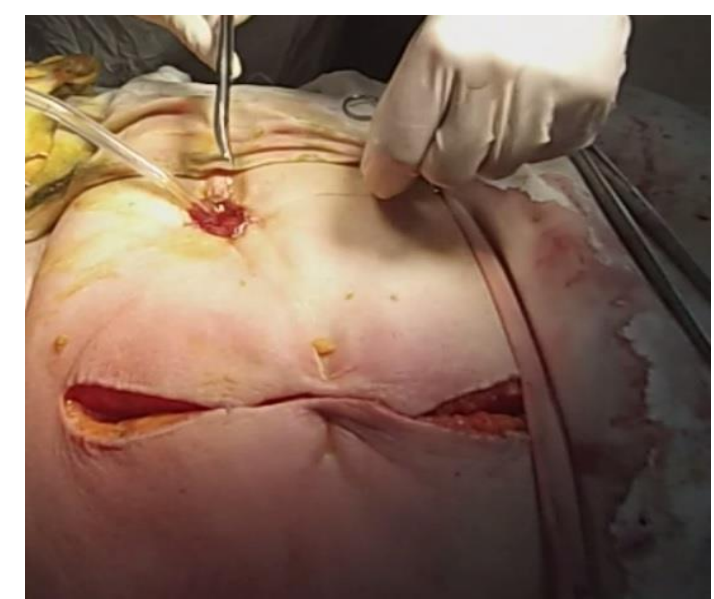

Figure 9 - Ileostoma aspect before abdominal wall closure 


\section{Postoperative recovery}

By the end of the procedure the ileostoma already presented intestinal transit. The patient recovered slowly. Following the operative procedure, antibiotherapy was induced (the antibiogram revealed sensitive group B streptococcus). Drainage on the tubes was minimum and the WBC reached $18 \mathrm{~K}$ the following day and $9 \mathrm{~K}$ on the fourth day. The CRP reached $200 \mathrm{mg} / \mathrm{L}$ the following day and dropped below $100 \mathrm{mg} / \mathrm{L}$ on the fourth day. The patient was discharged 14 days after admission.

\section{Discussions}

During the clinical diagnostic stage the patient's Alvarado score was five, but the consideration in this case was that an emergency procedure outweighed a diagnostic CT examination.

The anesthesia risk was considered, especially considering the age of the patient, the old bilateral leg edema, and that the patient was not under any medication (although the patient was later found to be suffering from diabetes, hypertension, atrial fibrillation and Alzheimer's disease). An epidural approach was unsuccessful as a result of the antalgic posture of the patient and the vertebral column deformations.

In considering the operative procedure, and although elderly patients benefit from a laparoscopic approach, in this case, the operative team decided that an open approach would be better suited because of the tenderness of the abdomen. The use of laparoscopy in the elderly has nevertheless significantly increased in recent years. Though this aspect is still debatable, laparoscopic appendectomy offers elderly patients with appendicitis a shorter length of hospital stay, fewer complications and lower mortality rates [10].

The surgical procedure and the histopathologic evaluation confirmed the diagnosis as phlegmonous appendicitis with a focal periappendicular abscess that fused in the mesentery, greater omentum, anterior abdominal muscles with a tendency of cutaneous fistulization.
A differential diagnosis was made of colonic carcinoma, abdominal abscess, mesenteric ischemia, abdominal abcess.

Compared with younger people with appendicitis the same pathology in the elderly is met with increased comorbidities, increased rates of perforation, postoperative morbidity, mortality, and hospital length of stay. Postoperative care is essential for a favorable recovery and outcome in elderly patients who present with a complicated case of acute appendicitis. In our reported case, the patient recovered well, with a good aspect of the ileostoma; bearing in mind the quality of life relative to the patient's age, a reintervention for an ileo-ileo anastomosis was to be considered.

\section{Conclusions}

The young clinician must bear in mind that even if appendicitis is a common surgical emergency and one of the most common causes of abdominal pain, the symptomatology is irregular, especially in the elderly (and also in young patients).

It is also worth noting that there are cases of appendicitis in the elderly in which an emergency intervention outweighs a diagnostic CT scan (even with the current rising trend of CT diagnostics, and regardless of the Alvarado score).

Even though the operating procedure for an appendectomy is well established, and considered to be a routine procedure, it is by no means regular yet alone untroubled. For the symptomatology may appear mild while at the same time the severity of the case may be increased.

\section{References}

[1]FitzHarris GP, Garcia-Aguilar J, Parker SC, et al: Quality of life after subtotal colectomy for slowtransit constipation: Both quality and quantity count. Dis Colon Rectum 46:433, 2003. [PubMed: 12682533].

[2]Vaizey CJ, Kamm MA, Roy AJ, et al: Doubleblind crossover study of sacral nerve stimulation for fecal incontinence. Dis Colon Rectum 43:298, 2000. [PubMed: 10733109]. 
[3]Stocchi L, Pemberton JH: Pouch and pouchitis. Gastroenterol Clin North Am 30:223, 2001. [PubMed: 11394032].

[4]Zmora O, Pikarsky AJ, Wexner SD: Bowel preparation for colorectal surgery. Dis Colon Rectum 2001:44, 1537.

[5]Karamanakos SN, Sdralis E, Panagiotopoulos S,

Kehagias I: Laparoscopy in the emergency setting: a retrospective review of 540 patients with acute abdominal pain. Surg Laparosc Endosc Percutan Tech. Apr 2010;20(2):119-24. [Medline].

[6]Dueholm S, Bagi P, Bud M: Laboratory aid in the diagnosis of acute appendicitis. A blinded, prospective trial concerning diagnostic value of leukocyte count, neutrophil differential count, and C-reactive protein. Dis Colon Rectum. Oct 1989;32(10):855-9. [Medline].

[7]Yee J, Akerkar GA, Hung RK, et al: Colorectal neoplasia: Performance characteristics of CT colonography for detection in 300 patients. Radiology 219:685,2001. [PubMed: 11376255].

[8]Greene FL PD, Fleming ID, Fritz A, et al: AJCC Cancer Staging Manual, 6th ed. New York: Springer, 2002.

[9]Dellinger, R. Phillip et al: Surviving Sepsis Campaign: International Guidelines for Management of Severe Sepsis and Septic Shock: 2012. Critical Care Medicine, Feb.2013, Vol.41, No2.

[10]Gunderson LL, Sargent DJ, Tepper JE, et al: Impact of $\mathrm{T}$ and $\mathrm{N}$ substage on survival and disease relapse in adjuvant rectal cancer: A pooled analysis. Int J Radiat Oncol Biol Phys 54:386, 2002. [PubMed: 12243812].

[11]Schneider C, Kharbanda A, Bachur R: Evaluating appendicitis scoring systems using a prospective pediatric cohort. Ann Emerg Med. Jun 2007; 49(6):778-84, 784.e1. [Medline].

[12]Yeh CC1, Wu SC, Liao CC, Su LT, Hsieh CH, Li TC: Laparoscopic appendectomy for acute appendicitis is more favorable for patients with comorbidities, the elderly, and those with complicated appendicitis: a nationwide populationbased study, Surg Endosc. 2011 Sep; 25(9):2932-42. [13]Brunicardi F, Andersen D, Billiar T, Dunn D, Hunter J, Matthews J, Pollock RE: Schwartz's Principles of Surgery, Ninth Edition; McGraw-Hill's - Sep 11, 2009.

[14]Garden OJ, Bradbury AW, Forsythe JLR, Parks RW: Principles \& Practice of Surgery, Adapted International Edition, 6th Edition, Churchill Livingstone Elsevier 2012. 